\title{
Perspectivas de aplicações tecnológicas de lodo gerado no processo de tratamento de água dos rios Negro e Solimões
}

\author{
Prospects of technological applications of \\ sludge from water treatment process of the \\ Negro and Solimões rivers
}

Gessica Zila Batista dos Santos ${ }^{1}$, João de Almeida Melo Filho ${ }^{1}$, Lizandro Manzato ${ }^{1,2}$

\begin{abstract}
${ }^{1}$ PPGEC/UFAM, Faculdade de Tecnologia, Setor Norte, Av. General Rodrigo Octávio Jordão Ramos, 6200, Coroado, 69080-005, Manaus, AM, Brasil.

${ }^{2}$ IFAM, Campus Manaus Distrito Industrial, Av. Governador Danilo de Matos Areosa, 1672, Distrito Industrial, 69075351, Manaus, AM, Brasil.

e-mail: gessicaz@hotmail.com, jalmeida26179@gmail.com, lizandro@ifam.edu.br
\end{abstract}

\section{RESUMO}

Este trabalho teve como objetivo caracterizar um subproduto do processo de tratamento de água, visando inseri-lo na cadeia produtiva da construção civil. Tal subproduto foi gerado em uma estação de tratamento de água (ETA), que realiza a captação de água bruta do Rio Negro e, eventualmente, do Rio Solimões. Para adequar a água desses mananciais aos padrões de potabilidade brasileiros, executa-se na ETA uma série de processos físico-químicos, os quais acarretam a geração do resíduo designado lodo de ETA. Visando identificar possíveis aplicações tecnológicas para o referido resíduo, fez-se uma pesquisa bibliográfica pertinente. Desse modo, constatou-se que esse tipo de subproduto necessita de beneficiamento prévio à utilização. Sendo assim, para tornar o lodo de ETA estudado uma matéria-prima apropriada, submeteu-se o mesmo a procedimentos de secagem, moagem e calcinação. Antes e após tais procedimentos, suas características foram determinadas por meio de Fluorescência de Raios X (FRX), Difração de Raios X (DRX), Termogravimetria (TG), dentre outras técnicas. Os resultados das caracterizações evidenciaram que mais de $80 \%$ da composição do lodo de ETA calcinado corresponde a óxidos de silício e alumínio. Acreditase que, após o beneficiamento, o lodo tornou-se uma matéria-prima econômica e ambientalmente sustentável, podendo ser utilizado como substituto parcial de argilas, na produção de materiais cerâmicos; substituto parcial de cimento Portland, em pastas, argamassas e concretos; aditivo mineral ou pozolana artificial; precursor ou agregado geopolimérico.

Palavras-chave: lodo de ETA, resíduo, construção civil, Rio Negro, Rio Solimões.

\section{ABSTRACT}

This work aimed to characterize a by-product of the water treatment process, aiming to insert it into the productive chain of construction. Such by-product was generated in a water treatment plant (WTP), which performs the capture of raw water from the Negro River and, eventually, from the Solimões River. To adapt the water from these sources to the Brazilian standards potable water, a series of physical-chemical processes are carried out at WTP, which lead to the generation of waste called as WTP sludge. Aiming to identify possible technological applications for this by-product, a pertinent bibliographical research was carried out. That way, it was verified that WTP sludge needs pretreatment prior to use. Like this, in order to make the studied WTP sludge an adequate raw material, the same was submitted to drying, grinding and calcination. Before and after such procedures, the sludge characteristics was determined by means of X-Ray Fluorescence (XRF), X-Ray Diffraction (XRD), Thermogravimetry (TG), among other techniques. The characterization results showed that more than $80 \%$ of the calcined sludge composition corresponds to silica and aluminum oxides. It is believed that, after processing, the sludge has become an economically and environmentally sustainable raw material, it can be used as partial substitute of clays, in the production of ceramic materials; 
partial substitute of Portland cement, in pastes, mortars and concretes; mineral additive or artificial pozzolana; geopolymer precursor or aggregate.

Keywords: WTP sludge, waste, construction, Negro River, Solimões River.

\section{INTRODUÇÃO}

O aumento da população mundial nos últimos séculos [1] tem provocado uma enorme pressão sobre os ecossistemas terrestres e aquáticos [2], fontes de energia e recursos naturais. A construção civil, cuja expansão é diretamente ligada ao crescimento populacional, está presente em todas as regiões do planeta e seu impacto ambiental é proporcional a sua tarefa social [3]. É um dos maiores setores da economia mundial e o maior consumidor de recursos naturais, visto que produz os bens de maiores dimensões físicas do planeta [3]. Para alcançar o desenvolvimento sustentável é necessário que toda a cadeia produtiva da construção civil passe por transformações significativas [3].

A produção do concreto, material amplamente utilizado na construção civil, está atrelada ao elevado consumo de recursos naturais e energia, bem como à degradação ambiental, por vezes, irreversível. Uma alternativa interessante para amenizar os impactos ambientais causados pelo concreto é a reciclagem. A reciclagem consiste na coleta e transformação de materiais residuais em produtos novos e úteis [4]. É classificada como reciclagem primária, quando o resíduo é transformado em novos produtos do mesmo tipo, e secundária, quando os resíduos são convertidos em produtos diferentes [4].

JOHN [3] propôs uma metodologia para conduzir, por meio da reciclagem, a transformação de um resíduo em um material de construção. Essa metodologia compreende as seguintes etapas: (a) seleção do resíduo, (b) levantamento de dados sobre a produção do resíduo, (c) caracterização detalhada do resíduo, (d) inventário de alternativas de reciclagem, (e) seleção da alternativa, (f) desenvolvimento do produto, (g) avaliação do produto, (h) estudo da viabilidade econômica e (i) transferência de tecnologia para o mercado.

Ao mesmo tempo que a indústria de materiais de construção investiga ações que a tornem ambiental e economicamente sustentável, outros setores industriais estão à procura de soluções adequadas para a destinação de seus resíduos. Uma realidade desse tipo é enfrentada pelas estações de tratamento de água ETAs, responsáveis pelo tratamento de água destinada ao abastecimento público. Com a finalidade de adequar a água aos padrões de potabilidade [5], na ETA, a matéria-prima (água bruta) é submetida a uma série de processos físico-químicos e, como na maior parte dos processos industriais, gera-se resíduo, nesse caso, um lodo.

Lodos de ETA são classificados como resíduos sólidos [6], por isso necessitam de destinação final ambientalmente adequada que, de acordo com a Política Brasileira de Resíduos Sólidos [7], "inclui a reutilização, a reciclagem, a compostagem, a recuperação e o aproveitamento energético [...]”. No Brasil, esse tipo de resíduo tem sido frequentemente lançado em cursos d'água [8, 9], prática que deve ser evitada pois se caracteriza como crime ambiental, principalmente nos casos em que a ETA não possui outorga para utilizar corpos hídricos para fins de diluição [10,11]. As ETAs do Brasil quando tratam seus lodos é para viabilizar seu transporte e disposição em aterros [9].

Em uma das ETAs que compõem o sistema de abastecimento de água da cidade de Manaus realiza-se a adução de água bruta em um ponto turístico da região amazônica conhecido como "Encontro das Águas". Nesse ponto, dois mananciais se encontram: Rio Negro e Rio Solimões. Na referida ETA, a água bruta é captada principalmente do Rio Negro mas, eventualmente, do Solimões. O Rio Negro é classificado como um rio de águas pretas $[12,13]$. Por ser abundante de substâncias orgânicas dissolvidas, apresenta coloração escura e um considerável nível de acidez [12].

O Rio Solimões-Amazonas é classificado como um rio de águas brancas [12, 13], que transportam grandes quantidades de sólidos suspensos, responsáveis por sua aparência lamacenta, amarelada ou ocre. Suas águas são extremamente turvas, compostas demasiadamente de sólidos, e por apresentarem muito pouco material orgânico, são levemente alcalinas ou neutras [12]. A ETA, cujo lodo foi utilizado nesse estudo, localiza-se próxima ao ponto de deposição de sedimentos trazidos pelo Rio Solimões-Amazonas [13].

Para tornar a água proveniente desses mananciais adequada aos padrões de potabilidade [5], é necessário submetê-la a processos de tratamento. É nesse contexto que, somente em Manaus, geram-se diariamente dezenas de toneladas de lodo. Uma ETA convencional produz cerca de 100.000 toneladas de lodo anualmente [14]. Esse resíduo é composto de sedimentos do solo local, certas substâncias dissolvidas e produtos químicos, tais como sais de ferro e/ou alumínio, adicionados à agua bruta durante os processos realizados na ETA [15].

Nas últimas décadas, diversos estudos foram conduzidos no intuito de inserir uma variedade de 
subprodutos industriais na cadeia produtiva da construção civil. Seguindo essa tendência, o presente trabalho teve como objetivo caracterizar o lodo de ETA gerado no processo de tratamento de água destinada ao abastecimento público da cidade de Manaus, visando ao aproveitamento desse resíduo pela construção civil. Para tanto, adotou-se, parcialmente, a metodologia proposta por JOHN [3].

\section{LODOS DE ETA: CARACTERIZAÇÃO E INVENTÁRIO DE ALTERNATIVAS DE RECICLAGEM}

Após selecionar o resíduo e realizar o levantamento de dados sobre a sua produção, seguindo a metodologia proposta por JOHN [3] , fez-se uma pesquisa bibliográfica para identificar as principais características de lodos de ETA e inventariar alternativas para a sua reciclagem. Geralmente, visando definir a destinação ou disposição desse tipo de resíduo, realiza-se previamente a sua ampla caracterização [16-21]. Assim, é possível escolher dentre as alternativas existentes a mais apropriada para cada tipo de lodo. Nesse estudo, em meio a diversas alternativas de gerenciamento de lodos de ETAs ateve-se àquelas direcionadas a aplicações tecnológicas, visando atender ao modelo de destinação final adequada previsto na legislação brasileira [7].

Diversos estudos têm sido desenvolvidos propondo opções de reciclagem de lodos de ETA [16-48]. Um inventário de algumas alternativas é apresentado na Tabela 1. Devido a sua similaridade com solos argilosos, a aplicação comumente dada a esses resíduos é a sua utilização como matéria-prima na preparação de produtos cerâmicos, principalmente tijolos [22-31]. Quanto à composição química, os principais constituintes verificados em lodos de ETA são os óxidos de silício ( $\mathrm{Si}$ ), alumínio (Al) e ferro (Fe), e no que concerne à composição mineralógica, a caulinita, a ilita, a hematita e o quartzo são as fases cristalinas comumente encontradas [9, 17, 19-28, 30, 32-34, 37-40, 42-48].

Tabela 1: Alternativas de aplicações tecnológicas para lodos de ETA.

\begin{tabular}{ll}
\hline ALTERNATIVA & REFERÊNCIA \\
\hline Produção de materiais cerâmicos & {$[22-31]$} \\
Produção de tijolo solo-cimento & {$[32]$} \\
Substituição de areia & {$[33,34,35]$} \\
Substituição parcial de cimento Portland & {$[36,37]$} \\
Pozolana artificial & {$[38,39,40]$} \\
Produção de compósito & {$[41,42]$} \\
Produção de geopolímeros - como precursor & {$[9,43-45]$} \\
Produção de geopolímeros - como agregado & {$[46,47,48]$} \\
\hline
\end{tabular}

$\mathrm{Na}$ Tabela 1 pode-se verificar que existem várias alternativas de aplicações tecnológicas para lodos de ETA, porém, independentemente da aplicação, observou-se que esse tipo de resíduo, na maioria das vezes, causou efeitos adversos à estrutura dos materiais aos quais fora incorporado. Tais efeitos estão associados, sobretudo, à elevada umidade e matéria orgânica, tipicamente presentes em lodos de ETA. Por isso, materiais produzidos à base desses resíduos exibem problemas como porosidade, fissuras e, principalmente, redução de resistência mecânica [9, 14, 22-24, 26, 27, 29, 30, 32-35, 37].

PAIXÃO et al. [24] estudaram os efeitos da adição de lodo de ETA nas características físicas de uma massa de cerâmica vermelha. Verificaram que a incorporação de até $10 \%$ em peso de lodo acarretou ao material investigado a diminuição de resistência à flexão e o aumento simultâneo de absorção de água e de porosidade aparente. Visando obter melhores resultados, beneficiou-se o lodo por meio de calcinação e moagem, antes de adicioná-lo à composição da massa cerâmica. Foi constatado que a cerâmica com adição de lodo calcinado apresentou maior resistência à flexão que àquela produzida com o lodo bruto.

VIEIRA et al. [26], ao realizaram incorporações de lodo de ETA em massa cerâmica, observaram em micrografia o aumento de defeitos microestruturais no material produzido. Relacionaram esses defeitos à combustão de matéria orgânica presente no lodo, que causou uma elevada perda de massa durante o processo de queima da cerâmica. Em tal estudo, sugeriu-se calcinar previamente o lodo a fim de reduzir perdas de massa e minimizar possível efeito adverso. VITORINO et al. [27] utilizaram três tipos de resíduos gerados em ETA no preparo de massa cerâmica argilosa. Os corpos de prova moldados foram queimados a $700{ }^{\circ} \mathrm{C}$. Após a queima, ocorreu uma perda significativa de massa no lodo, devido à combustão de matéria orgânica e a eliminação de água de constituição da caulinita, causando porosidade no material cerâmico preparado.

TEIXEIRA et al. [30], ao incorporarem lodo de ETA na composição de materiais cerâmicos, 
observaram o aumento da absorção de água e a diminuição concomitante da massa específica aparente e da resistência à flexão das amostras. Associaram esses efeitos, principalmente, à concentração elevada de matéria orgânica no lodo (29\%), cuja combustão estaria aumentando a porosidade do material durante a queima. RODRIGUES e HOLANDA [32], ao empregarem lodo de ETA na composição de tijolos solocimento, constataram a diminuição da resistência mecânica dos corpos cimentícios. Relacionaram tal resultado, dentre outros fatores, à elevada proporção de matéria orgânica presente na amostra, de 25,85\%.

RODRÍGUEZ et al. [37], ao adicionarem lodo de ETA sem nenhum tratamento térmico em substituição parcial ao cimento Portland em argamassa, observaram uma diminuição significativa de resistência mecânica das amostras nas quais incorporou-se teores de lodo, o que estaria relacionado, talvez, à matéria orgânica presente nesse resíduo. WAIJAREAN et al. [43] investigaram a utilização de lodo de ETA como matéria-prima fonte de aluminossilicatos para sintetizar geopolímeros. Os resultados obtidos em ensaios de resistência à compressão revelaram que o material produzido com lodo sem calcinação só desenvolveu resistência mecânica após os 60 dias de idade $(0,76 \mathrm{MPa})$, pois não ocorreu a formação de geopolímero nas idades iniciais.

Todos esses estudos evidenciam a necessidade de se beneficiar o lodo de ETA antes de incorporá-lo à composição de materiais de construção. A adoção de processos de beneficiamento, como a calcinação, pode melhorar o desempenho do lodo de ETA como matéria-prima, além de viabilizar que maiores volumes do referido resíduo sejam reciclados. Em oposição aos efeitos adversos mencionados nos estudos citados, quando o lodo de ETA foi previamente beneficiado por meio de tratamento térmico e/ou mecânico resultados mais satisfatórios foram obtidos [24,38-40,43-45]. No presente trabalho, os processos adotados no beneficiamento do lodo tiveram como objetivo otimizar seus efeitos na estrutura do produto ao qual for incorporado.

\section{MATERIAIS E MÉTODOS}

Seguindo a metodologia proposta por JOHN [3], após selecionar o resíduo (a), realizar o levantamento de dados sobre a sua produção (b), o passo seguinte é caracterizá-lo detalhadamente (c). Nesse sentido, para representar as duas condições distintas sob as quais o lodo utilizado nesse trabalho poderia se apresentar, foram efetuadas duas coletas desse resíduo. Na primeira coleta, a captação de água bruta era essencialmente do Rio Negro. Na segunda coleta, a água bruta estava sob influência do Rio Solimões.

Apenas na análise de granulometria empregou-se o lodo da forma que foi coletado, ou seja, em estado "in natura". Todas as demais análises do lodo foram executadas sob duas condições: após a secagem em estufa, a $110{ }^{\circ} \mathrm{C}$ por 8 horas, seguida de moagem em moinho de bolas (designado "lodo seco"); e após a calcinação, a $750{ }^{\circ} \mathrm{C}$ por 6 horas (denominado "lodo calcinado"). Como nesse estudo foram utilizados dois diferentes tipos de lodo, para facilitar o entendimento, o lodo derivado da água do Rio Negro foi designado "lodo do Rio 1", enquanto o lodo sob influência do Rio Solimões foi denominado "lodo do Rio 2".

\subsection{Materiais}

O lodo utilizado nesse trabalho foi coletado na ETA do PROAMA, também conhecida como ETA Ponta das Lajes, componente do sistema de abastecimento de água de Manaus. Quando coletado na ETA, o lodo havia sido submetido a um processo de centrifugação, mas ainda apresentava um aspecto bastante úmido. Os procedimentos adotados em seu beneficiamento e caracterização serão especificados a seguir.

\subsubsection{Procedimentos adotados no beneficiamento do lodo de ETA}

\subsubsection{Secagem em estufa}

A secagem do lodo foi executada em um forno do tipo estufa. Com o objetivo de estimar o tempo ideal para retirar o excesso de umidade presente no lodo, foram efetuados testes utilizando um analisador de umidade. Após cada ciclo de secagem em estufa, submetia-se uma amostra do material seco à análise de umidade. Dessa forma, foi possível fixar o tempo e a temperatura adequados para o procedimento de secagem em $110{ }^{\circ} \mathrm{C}$ por 8 horas, pois sob tais condições a amostra de lodo seco submetida à análise apresentou apenas $6,3 \%$ de umidade e o nível de dureza do material foi considerado adequado para o processo de moagem mecânica.

\subsubsection{Moagem}

Quando submetidas a tratamento térmico, as partículas de materiais argilosos tendem a se aglomerar [49]. 
Quando isso acontece a moagem mecânica se faz necessária. O lodo da forma como recebido era basicamente composto de partículas finas, porém, após a secagem em estufa, suas partículas se agregaram, adquirindo um aspecto de pequenas rochas. Para desagregá-las, o lodo devidamente seco foi submetido à moagem mecânica, realizada em um moinho de bolas cerâmico universal, com capacidade de 7,5 litros. Como corpos moedores foram utilizadas esferas cerâmicas cujos diâmetros mediam, em média, 45, 27 e 14 milímetros. Admitiu-se uma proporção de bolas/lodo de 2:1. Usou-se um terço da capacidade do moinho, por um período de 2 horas.

\subsubsection{Peneiramento}

O material devidamente seco e moído, foi peneirado manualmente em uma peneira da ABNT $\mathrm{n}^{\circ} 100$ (abertura da malha de $150 \mu \mathrm{m}$ ), com o auxílio de um pincel, a fim de possibilitar a remoção de partículas grosseiras remanescentes e um processo de calcinação uniforme. Apenas o lodo proveniente do Rio Negro foi submetido a esse procedimento.

\subsubsection{Calcinação}

Neste procedimento utilizou-se um forno do tipo mufla, a $750{ }^{\circ} \mathrm{C}$ por 6 horas. Devido às semelhanças químicas e mineralógicas entre lodos de ETA e certas argilas cauliníticas, os parâmetros adotados na calcinação foram definidos de acordo com a literatura referente a esses minerais [50, 51]. Estudos conduzidos por RASHAD [50] e SABIR et al. [51] evidenciaram que a temperatura ideal para a calcinação de materiais argilosos está situada entre 600 e $850{ }^{\circ} \mathrm{C}$. O tempo pode variar de horas a segundos, dependendo do tipo de forno utilizado. A calcinação abaixo de $700{ }^{\circ} \mathrm{C}$ resulta em um material menos reativo, que apresenta caulinita residual, enquanto a calcinação acima de $850^{\circ} \mathrm{C}$ induz a recristalização do material, acarretando o declínio de sua reatividade.

\subsection{Caracterização do lodo de ETA}

A composição química do lodo foi determinada por Espectrometria de Fluorescência de Raios X (FRX), por energia dispersiva. A composição mineralógica do lodo foi estimada por Difração de Raios X (DRX), utilizando-se um difratômetro de raios $\mathrm{X}$ com goniômetro Theta/Theta e tubo de raios $\mathrm{X}$ cerâmico de anodo de $\mathrm{Cu}(\mathrm{K} \alpha 1$ 1,5406 Å). A aquisição de dados foi feita com o auxílio do software Data Collector, versão 5.1a.

As medidas de DRX foram obtidas sob as seguintes condições instrumentais: voltagem $(\mathrm{kV})$ : 40; corrente (mA): 40; ângulo de varredura $\left({ }^{\circ} 2 \theta\right)$ : 10-100; passo de $\left({ }^{\circ} 2 \theta\right): 0,02$. O tratamento dos dados e a identificação das fases minerais foram realizados utilizando o programa X'Pert HighScore Plus, comparando o difratograma obtido com padrões (fichas) do banco de dados do ICDD PDF-2 Release 2003. As fichas são específicas para cada mineral (por exemplo, quartzo $=01-089-8936$ ), podendo haver diferentes fichas para o mesmo mineral.

O tamanho e distribuição das partículas do lodo de ETA, em estado in natura e após a calcinação, foram obtidos pelo método de espalhamento de luz (laser), utilizando-se um granulômetro. Para desagregar as amostras, foram usados como dispersante 20 mililitros de amônia. Considerando as semelhanças do lodo de ETA com solos, inferiu-se que seria conveniente classificar o tamanho de suas partículas de acordo com a terminologia para solos definida pela norma brasileira [52].

Para determinar a massa específica do lodo utilizou-se um picnômetro a gás (hélio). O resultado foi obtido a partir do cálculo da média aritmética de cinco leituras. A área superficial específica do lodo foi determinada pelo método de Brunauer, Emmett e Teller - BET, utilizando-se um analisador de área superficial BET. O comportamento térmico do lodo foi avaliado por Análises Termogravimétricas (TG/DTG). Essas análises foram executadas com o equipamento operando a uma taxa de aquecimento de $10{ }^{\circ} \mathrm{C}$ por minuto, até $1000^{\circ} \mathrm{C}$, com fluxo de gás Nitrogênio 5.0, de 30 mililitros por minuto.

\section{RESULTADOS E DISCUSSÃO}

\subsection{Composição química dos lodos}

A composição química dos lodos, antes e após a calcinação, consta na Tabela 2. De acordo com a literatura $[16,30]$, variáveis como o tipo de coagulante, o mês e a região de coleta, além do manancial que pode, por exemplo, apresentar variações sazonais de turbidez, implicam marcadamente na quantidade e nas características do lodo formado. Os resultados confirmaram o que já era esperado, pois a composição química do lodo variou significativamente de acordo com o período de coleta, corroborando, portanto, a 
literatura.

Verificou-se que ambos os rios influenciaram grandemente as características do lodo. Sabe-se que a coloração escura das águas do Rio 1 se deve à presença de matéria orgânica decomposta e óxidos de ferro nelas dissolvidos, enquanto as águas do Rio 2, por transportarem grandes quantidades de sólidos suspensos (argilas, siltes e areias finas), exibem coloração lamacenta [12,13]. Consequentemente, o lodo do Rio 1, influenciado pelas características do referido manancial, apresentou o maior percentual de óxidos de ferro $\left(\mathrm{Fe}_{2} \mathrm{O}_{3}\right)$, enquanto o lodo do Rio 2 exibiu percentuais elevados de óxidos de silício $\left(\mathrm{SiO}_{2}\right)$, provavelmente, relacionados à grande quantidade de sólidos suspensos presentes na água bruta do respectivo manancial. Quanto ao percentual de óxidos de alumínio $\left(\mathrm{Al}_{2} \mathrm{O}_{3}\right)$, acentuado em ambos os lodos, certamente está relacionado ao tipo de coagulante utilizado na ETA, o sulfato de alumínio $\left(\mathrm{Al}_{2}\left(\mathrm{SO}_{4}\right)_{3}\right.$. No que concerne a metais pesados, não foram detectados.

Tabela 2: Composição química dos lodos, expressa em óxidos, antes e após a calcinação.

\begin{tabular}{lcccccccccc}
\hline Óxidos (Peso \%) & $\mathbf{S i O}_{\mathbf{2}}$ & $\mathbf{A l}_{\mathbf{2}} \mathbf{O}_{\mathbf{3}}$ & $\mathbf{F e}_{\mathbf{2}} \mathbf{O}_{\mathbf{3}}$ & $\mathbf{K}_{\mathbf{2}} \mathbf{O}$ & $\mathbf{T i O}_{\mathbf{2}}$ & $\mathbf{M g O}$ & $\mathbf{C a O}$ & $\mathbf{P}_{\mathbf{2}} \mathbf{O}_{\mathbf{5}}$ & $\mathbf{S O}_{\mathbf{3}}$ & Outros \\
\hline Rio 1: Lodo seco & 39,94 & 37,62 & 14,08 & 2,45 & 1,57 & 0,66 & 0,71 & 0,92 & 1,01 & 1,03 \\
Rio 1: Lodo calcinado & 40,73 & 42,39 & 10,94 & 2,18 & 1,26 & 0,95 & 0,56 & 0,63 & 0 & 0,36 \\
Rio 2: Lodo seco & 55,25 & 25,72 & 10,61 & 3,52 & 1,04 & 1,57 & 0,71 & 0,62 & 0,48 & 0,49 \\
Rio 2: Lodo calcinado & 55,78 & 27,16 & 9,54 & 3,32 & 0,95 & 1,69 & 0,65 & 0,55 & 0 & 0,36 \\
\hline
\end{tabular}

Como acontece nos materiais pozolânicos, amplamente utilizados na construção civil, a somatória dos percentuais de $\mathrm{SiO}_{2}$ e de $\mathrm{Al}_{2} \mathrm{O}_{3}$ representou mais de $80 \%$ da composição de ambos os lodos calcinados, um forte indicativo de atividade pozolânica que deverá ser avaliado em estudo específico, uma vez que a atividade pozolânica está relacionada não apenas à composição elevada de $\mathrm{SiO}_{2}$ e $\mathrm{Al}_{2} \mathrm{O}_{3}$, mas também à estrutura do material: mais amorfa, mais ativa [37]. Além disso, esses percentuais elevados de $\mathrm{SiO}_{2}$ e de $\mathrm{Al}_{2} \mathrm{O}_{3}$ assinalam que tais resíduos podem ser aproveitados como matéria-prima na produção de geopolímeros [9, 43-48].

\subsection{Composição mineralógica dos lodos}

Os resultados das análises mineralógicas apresentados na Figura 1, referentes ao lodo do Rio 1, indicaram que antes da calcinação, os minerais presentes no lodo eram o quartzo $\alpha$ (01-089-8936), o rutilo (01-0881174), a caulinita (01-089-6538) e a cristobalita leve (01-076-0938). Após a calcinação, os minerais quartzo (01-083-0539) e rutilo (01-077-0442), apesar de parecerem inalterados, correspondem a outros padrões cristalográficos. No lodo calcinado também foi identificado o mineral muscovita (01-080-0743).

A Figura 2 exibe os resultados das análises mineralógicas referentes ao lodo do Rio 2. Antes da calcinação, esse resíduo apresentava como fases cristalinas o quartzo $\alpha$ (01-089-8935), a caulinita, sob dois diferentes padrões cristalográficos - (01-078-2109) e (01-075-0938), além de possíveis fases de ortoclásio (01-076-0823). Após a calcinação, foram identificadas fases correspondentes a quartzo $\alpha$ (01-089-8936), hematita (01-085-0599), anortita (01-073-0265), ferrosilita (01-072-1509), e ainda prováveis fases de ortoclásio (00-019-0931). A fase de quartzo $\alpha$ (01-089-8935) presente no lodo do Rio 2 antes da calcinação também é diferente da verificada após esse procedimento (01-089-8936). 


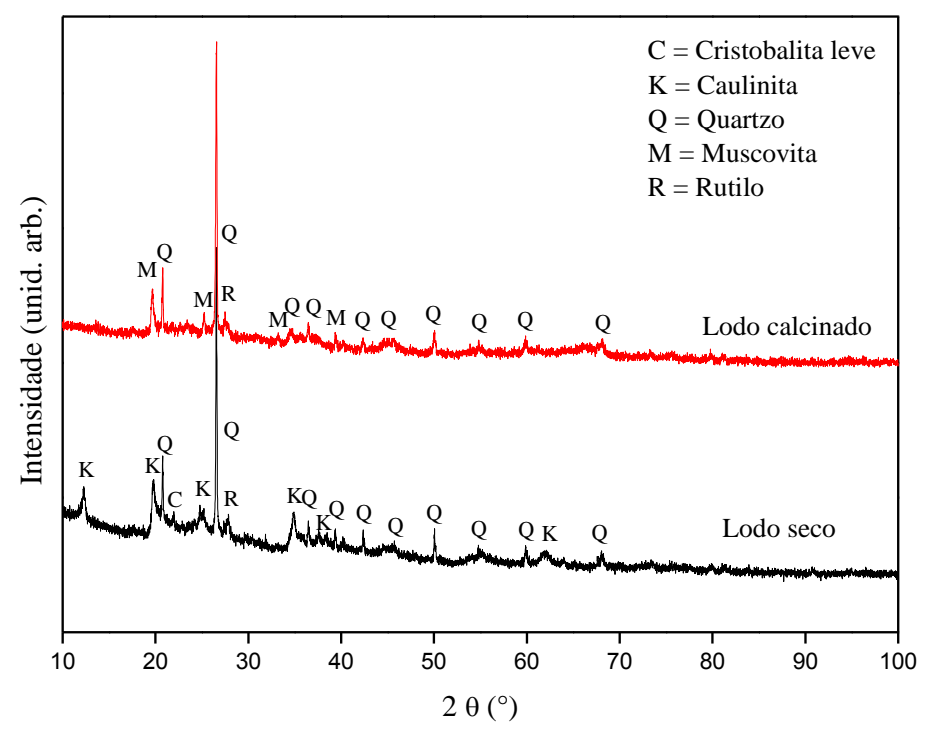

Figura 1: Difratogramas do lodo do Rio 1, antes e após a calcinação.

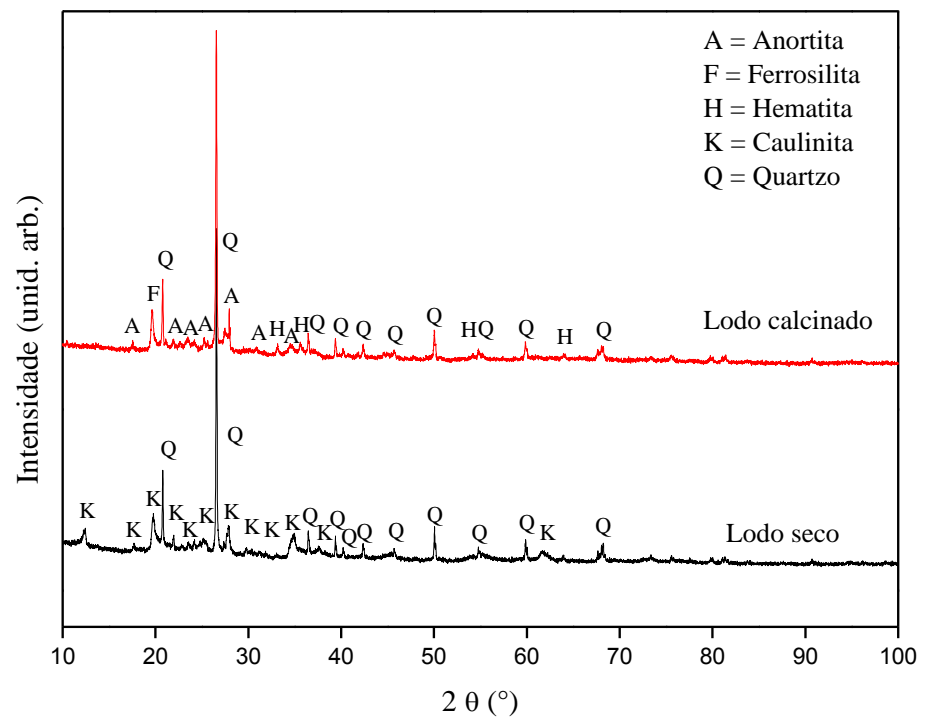

Figura 2: Difratogramas do lodo do Rio 2, antes e após a calcinação.

Observou-se que após a calcinação as fases cristalinas referentes à caulinita desapareceram, sendo assim, considera-se que os parâmetros adotados nesse procedimento foram eficientes para proporcionar a desidroxilação da caulinita. Apesar do lodo do Rio 1 conter elevado percentual de óxidos de ferro, como indicava a literatura [13], e conforme assinalaram os resultados das análises químicas, somente no lodo do Rio 2 foi possível identificar fases cristalinas de compostos de ferro - ferrosilita e hematita. Sugere-se que no lodo do Rio 1 os óxidos de ferro encontram-se em fase amorfa, o que dificultou sua identificação por meio de DRX.

Todas as fases cristalinas identificadas em ambos os lodos são típicas de solos argilosos [49, 50, 51]. Entretanto, verificou-se que, diferentemente do padrão que os solos argilosos cauliníticos exibem após a calcinação, os difratogramas dos lodos não apresentaram o halo típico de materiais amorfos, indicativo de maior reatividade. Desse modo, é presumível que a reatividade do lodo de ETA calcinado seja inferior, por exemplo, à de argilas calcinadas. Mas isso não prejudicará seu emprego como aditivo mineral ou pozolana de 
baixa reatividade [36-40], ou como matéria-prima geopolimérica [9, 43-48].

\subsection{Tamanho e distribuição das partículas dos lodos}

Pela norma brasileira [52] os solos são definidos, de acordo com sua granulometria como: argilas, quando apresentam dimensões menores que $0,002 \mathrm{~mm}$; como siltes, quando suas partículas exibem diâmetros entre 0,002 $\mathrm{mm}$ e 0,06 mm; e como areias, quando suas partículas possuem diâmetros compreendidos entre 0,06 $\mathrm{mm}$ e 2,0 mm. Sendo assim, variam entre 2 e 2000 micrômetros $(\mu \mathrm{m})$. Na Figura 3 são exibidas as curvas granulométricas dos lodos, antes e após a calcinação. Essas curvas correspondem basicamente a siltes e argilas.

As curvas granulométricas representam, em porcentagens, a variação do tamanho de grãos no volume de lodo analisado. Observou-se que o lodo in natura do Rio 1 era essencialmente constituído de partículas finas, dando-se a ideia de que a moagem mecânica não teria causado efeitos representativos na granulometria dos lodos. Entretanto, o processo de moagem foi determinante no ajustamento da finura desses materiais. As partículas de lodo quando calcinadas se agregaram, reação que ocorre em partículas argilosas quando são submetidas a tratamento térmico [49], e para tornarem-se finas novamente necessitaram de moagem mecânica.

Na Tabela 3 constam os diâmetros médios das partículas dos dois lodos. Comparando-se o diâmetro $\mathrm{D}_{10}$ dos lodos in natura, verificou-se que o lodo do Rio 2 se mostrou o mais grosseiro, o que também pode ser visualizado em sua respectiva curva granulométrica, bem próxima de $10 \mu \mathrm{m}$ (Figura 3). A granulometria desse resíduo é condizente com as características sedimentológicas do manancial que o influenciou, abundante de sólidos em suspensão [13]. Além disso, o lodo calcinado do Rio 2 também ultrapassou a granulometria correspondente a siltes e argilas $\left(\mathrm{D}_{90}\right)$, apresentando percentuais de partículas enquadradas como areia. Mas isto se deve exclusivamente ao fato desse lodo não ter sido peneirado, pois o lodo do Rio 1, calcinado e previamente peneirado, não exibiu partículas maiores que $100 \mu \mathrm{m}$, uma vez que essas foram retidas pela peneira utilizada no processo.

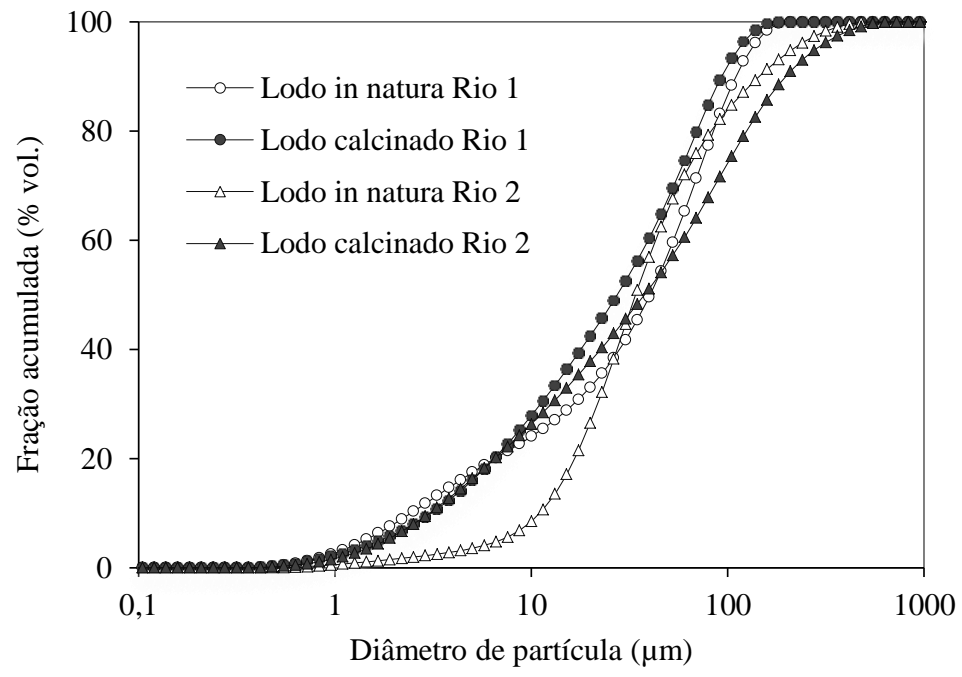

Figura 3: Tamanho e distribuição das partículas dos lodos, antes e após a calcinação.

Analisando-se juntamente as curvas granulométricas e os diâmetros médios dos lodos calcinados, verificou-se que o peneiramento adotado pouco interferiu na granulometria dos mesmos. Considerando as proximidades de tamanhos das partículas dos lodos calcinados, dependendo da aplicação que se pretenda dar a tais materiais, o procedimento de peneiramento pode ser desnecessário. Se for o caso, para auxiliar na determinação da composição granulométrica ótima, pode-se, por exemplo, utilizar o diagrama de Winkler. Tal ferramenta indica a dosagem de partículas finas, médias e grossas a serem utilizadas na preparação de produtos cerâmicos. Na literatura, o diagrama de Winkler assinalou claramente que um lodo de ETA específico era apropriado para a fabricação de produtos cerâmicos de alta qualidade [17]. 
Tabela 3: Tamanho das partículas dos lodos, antes e após a calcinação.

\begin{tabular}{lllll}
\hline & RIO 1 & RIO 1 & RIO 2 & RIO 2 \\
\hline Diâmetro $(\mu \mathrm{m})$ & Lodo in natura & Lodo calcinado & Lodo in natura & Lodo calcinado \\
\hline $\mathrm{D}_{10}$ & 2,44 & 3,08 & 11,05 & 3,03 \\
$\mathrm{D}_{50}$ & 40,30 & 27,39 & 33,99 & 37,69 \\
$\mathrm{D}_{90}$ & 109,77 & 93,01 & 144,48 & 197,15 \\
\hline
\end{tabular}

\subsection{Massa específica e área superficial específica dos lodos}

$\mathrm{Na}$ Tabela 4 constam os resultados das análises de massa específica e área superficial específica dos lodos, antes e após a calcinação. No que diz respeito à massa específica, observou-se que o lodo seco do Rio 1 apresentou valor significativamente inferior ao seu análogo do Rio 2. Porém, após a calcinação, os valores de massa específica de ambos os lodos se aproximaram. Sendo assim, admite-se que os processos de moagem e calcinação foram eficientes, pois uniformizaram os valores de massa específica dos dois lodos.

Quanto à área superficial específica, ao comparar os lodos secos, verificou-se que o lodo do Rio 1 exibiu o maior valor. As partículas desse resíduo, com elevado teor de matéria orgânica, talvez por serem menos densas, o que é condizente com a sua respectiva massa específica, sofreram mais impacto durante a moagem mecânica, tornando-se mais finas e mais irregulares. Vale ressaltar que tanto o lodo seco quanto o lodo calcinado de ambos os rios foram analisados após a moagem. Contudo, observou-se que após a calcinação houve um aumento na área superficial específica do lodo do Rio 1. Presume-se que nesse processo ocorreu a combustão da matéria orgânica, acarretando a perda de massa. Desse modo, as partículas do lodo se tornaram mais finas ainda e, consequentemente, com maior área superficial.

No lodo do Rio 2 observou-se um comportamento totalmente oposto. Após a calcinação, ocorreu a diminuição da área superficial específica. Esses resultados evidenciaram a necessidade de controle do processo de moagem, que deverá ser ajustado de acordo com o uso que se fará do lodo, uma vez que valores elevados de área superficial específica poderão causar o aumento da demanda de água nos materiais produzidos à base de lodo. Por outro lado, valores menores poderão comprometer a reatividade do material.

Tabela 4: Massa específica e área superficial específica dos lodos, antes e após a calcinação.

\begin{tabular}{llcc}
\hline RIO & ESTADO DO LODO & $\begin{array}{r}\text { MASSA ESPECÍFICA } \\
\left(\mathbf{g} / \mathbf{c m}^{\mathbf{3}}\right)\end{array}$ & $\begin{array}{c}\text { ÁREA SUPERFICIAL ESPECÍFICA BET } \\
\left.\mathbf{( m}^{\mathbf{2}} \mathbf{g}\right)\end{array}$ \\
\hline 1 & Seco & 1,95 & 38,1 \\
1 & Calcinado & 2,89 & 49,0 \\
2 & Seco & 2,59 & 21,8 \\
2 & Calcinado & 2,85 & 14,3 \\
\hline
\end{tabular}

\subsection{Comportamento térmico dos lodos}

Nas Figuras 4 e 5 constam as curvas termogravimétricas (TG), indicando as perdas de massa, e as respectivas derivadas (DTG), exibindo os eventos térmicos apresentados pelos lodos quando expostos a variadas temperaturas. Os resultados dessas análises são importantes para auxiliar na compreensão do comportamento desses resíduos quando submetidos à queima. Diversos estudos mostraram que o emprego de lodos de ETA sem o devido tratamento térmico causa efeitos adversos aos materiais produzidos [9, 14, 22-24, 26, 27, 29 , 30,32-35,37]. Portanto, quando se deseja reciclar tais resíduos é indispensável conhecer o seu comportamento térmico, pois a reatividade de lodos de ETA, bem com a sua interação positiva com os demais componentes de um produto, dependem da realização de um tratamento térmico adequado.

No lodo do Rio 1 (Figura 4), previamente seco em estufa a $110{ }^{\circ} \mathrm{C}$ por 8 horas, vários eventos térmicos foram identificados. O primeiro, que se estendeu até aproximadamente $120{ }^{\circ} \mathrm{C}$, na literatura é associado à eliminação de água, enquanto o segundo, que iniciou após $200{ }^{\circ} \mathrm{C}$ e se propagou até $850{ }^{\circ} \mathrm{C}$, é relacionado a processos de desidroxilação de minerais, à decomposição de matéria orgânica e de compostos inorgânicos como o sulfato de alumínio [17, 18, 20, 22, 23, 27, 30, 31, 37, 39, 40].

Os eventos térmicos exibidos pelo lodo seco do Rio 2 (Figura 5), possivelmente, estão relacionados a essas mesmas causas, embora tenham ocorrido em menor proporção. Comparando-se os termogramas dos lodos secos, verificou-se uma elevada perda de massa no lodo do Rio 1, cerca de 50\%. Esses resultados 
podem estar relacionados à presença abundante de matéria orgânica nas águas do Rio 1 [12, 13, 18]. De forma oposta, o lodo seco do Rio 2 exibiu pouca perda de massa pois, diferentemente do Rio 1, as águas que influenciaram esse resíduo transportam muitos sedimentos inorgânicos, que são menos suscetíveis à queima.

Nesse trabalho, adotou-se como parâmetros de calcinação a temperatura de $750{ }^{\circ} \mathrm{C}$ por 6 horas. Porém, o lodo do Rio 1 parecia requerer uma temperatura de queima maior que a empregada, pois apresentou em sua composição material residual até, aproximadamente, $850{ }^{\circ} \mathrm{C}$, corroborando as análises termogravimétricas realizadas por BOTERO [18], que também avaliou o comportamento térmico de um lodo de ETA gerado sob influência do Rio 1. Pelo termograma do lodo seco do Rio 2, podia-se inferir que uma temperatura de no máximo $600{ }^{\circ} \mathrm{C}$ seria aceitável para a calcinação desse resíduo. Contudo, a literatura indica que a temperatura ideal para a calcinação de materiais argilosos está situada entre 600 e $850{ }^{\circ} \mathrm{C}[50$, 51].

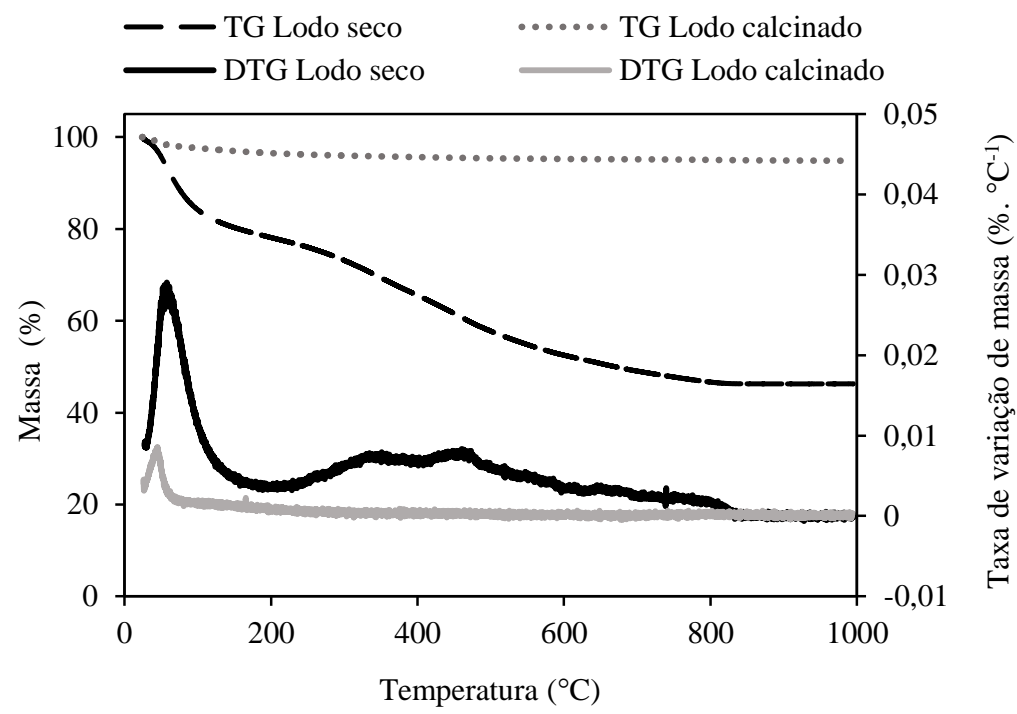

Figura 4: Comportamento térmico do lodo do Rio 1, antes e após a calcinação.

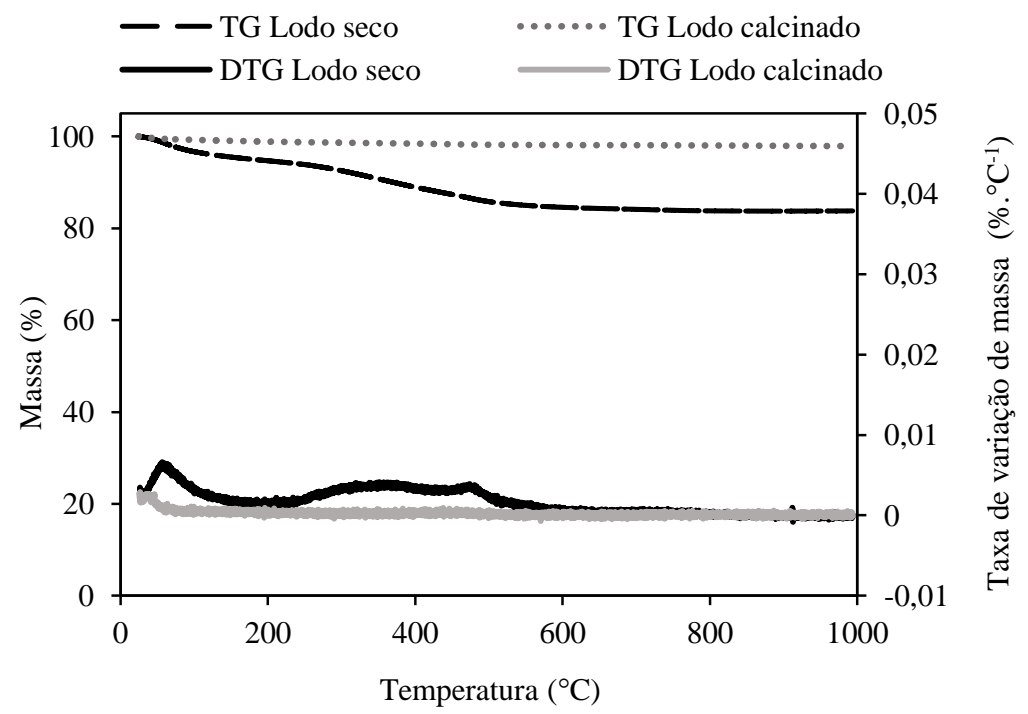

Figura 5: Comportamento térmico do lodo do Rio 2, antes e após a calcinação.

Pelos termogramas, verificou-se que ambos os lodos calcinados exibiram estabilidade térmica, ao menos até $1000{ }^{\circ} \mathrm{C}$. Apenas no termograma referente ao lodo calcinado do Rio 1 (Figura 4) pôde-se observar um pico em torno de $50^{\circ} \mathrm{C}$. Esse pico se deve, provavelmente, à remoção de umidade adquirida pelo material durante o armazenamento. Como os lodos calcinados não exibiram mais perdas de massa nem eventos térmicos significativos, conclui-se que o processo de calcinação adotado foi eficiente, corroborando a 
literatura [50, 51]. Do ponto de vista econômico, esses resultados são relevantes pois comprovaram que ambos os lodos podem ser submetidos à queima sob as mesmas condições estabelecidas para materiais argilosos. Sendo assim, não requerem maiores temperatura e tempo de calcinação, que poderiam onerar o processo, elevando o consumo energético e encarecendo o produto final.

\section{CUSTOS E POSSÍVEIS APLICAÇÕES PARA LODOS DE ETA CALCINADOS}

Seguindo a metodologia proposta por JOHN [3], após selecionar o resíduo (a), realizar o levantamento de dados sobre a sua produção (b), caracterizá-lo detalhadamente (c) e inventariar as alternativas para a sua reciclagem (d), os passos seguintes são: selecionar uma alternativa de reciclagem (e), desenvolver o produto (f), avaliá-lo (g), estudar sua viabilidade econômica (h) e transferi-lo para o mercado (i). No presente trabalho, apenas parte dessa metodologia foi concluída. No que diz respeito à viabilidade econômica, admitese que os métodos de secagem, moagem, calcinação e peneiramento conferem custos ao lodo de ETA. Contudo, esses processos são os mesmos utilizados na produção de metacaulim, produto amplamente comercializado.

Sendo assim, infere-se que o custo final do lodo beneficiado seja próximo ao de metacaulim comercial. E estimar esse custo é uma tarefa bastante relativa pois existem diferentes métodos de moagem, peneiramento e calcinação [50], os quais são definidos de acordo com a reatividade esperada e a finalidade de aplicação do material. Por se tratar de um resíduo, a reatividade do lodo calcinado poderá não ser a mesma de um metacaulim comercial. Por outro lado, a adoção dos processos de secagem, moagem e calcinação se mostraram satisfatórios na remoção de umidade e matéria orgânica, os principais responsáveis pelos efeitos adversos associados à reciclagem de lodos de ETA.

Consequentemente, espera-se que os materiais produzidos à base de lodo de ETA beneficiado adéquem-se aos padrões de qualidade equiparados aos de materiais de construção disponíveis no mercado. Considerando que o custo atrelado ao beneficiamento de lodos de ETA seja competitivo, presume-se que diferentes indústrias de materiais de construção possam incorporar esse tipo de resíduo em seus processos produtivos. Acredita-se que após o beneficiamento o lodo tornou-se uma matéria-prima econômica e ambientalmente sustentável, podendo ser utilizado em substituição parcial a argilas, na produção de materiais cerâmicos [22-31]; em substituição parcial ao cimento Portland em pastas, argamassas e concretos [36, 37]; como aditivo mineral ou pozolana artificial [36-40]; como precursor [9, 43-45] ou agregado [46, 47, 48] geopolimérico.

\section{CONCLUSÕES}

Com base na pesquisa bibliográfica realizada, concluiu-se que a incorporação de lodos de ETA in natura causa defeitos estruturais em materiais de construção. Considerando que resultados mais satisfatórios foram obtidos quando tais resíduos foram submetidos previamente a tratamento térmico e/ou mecânico, decidiu-se beneficiar o lodo de ETA utilizado nesse trabalho por meio de secagem, moagem, calcinação e peneiramento. Antes e após tais procedimentos, caracterizou-se o resíduo utilizando técnicas de FRX, DRX, TG, dentre outras. Desse modo, foi possível avaliar as mudanças ocorridas em suas características.

Os resultados de FRX demonstraram que mais de $80 \%$ da composição do lodo calcinado, gerado sob a influência das características dos rios Negro e Solimões, corresponde à somatória dos óxidos $\mathrm{SiO}_{2}$ e $\mathrm{Al}_{2} \mathrm{O}_{3}$. Já os resultados de DRX indicaram que as principais fases cristalinas presentes nos lodos são referentes ao quartzo e à caulinita, que sofreu desidroxilação devido à calcinação. As análises de granulometria, massa e área superficial evidenciaram que as partículas do lodo podem ser ajustadas de acordo com os parâmetros adotados no beneficiamento: moagem, peneiramento e calcinação. As análises térmicas confirmaram que o tratamento térmico é indispensável para o lodo sob influência do Rio Negro, uma vez que esse resíduo apresenta elevada perda de massa, cerca de 50\%, devido à combustão de matéria orgânica.

Os procedimentos de moagem, peneiramento e calcinação adotados no beneficiamento do lodo são os mesmos empregados na produção de metacaulim, produto amplamente comercializado. Os resultados obtidos nesse trabalho são bastante sugestivos de que o lodo gerado no processo de tratamento de água captada dos rios Negro e Solimões, se devidamente beneficiado, pode ser inserido na cadeia produtiva da construção civil. Nesse sentido, sugere-se que o resíduo estudado pode ser utilizado como substituto parcial de argilas, na produção de materiais cerâmicos; substituto parcial de cimento Portland, em pastas, argamassas e concretos; aditivo mineral ou pozolana artificial; precursor ou agregado geopolimérico. Conclui-se, portanto, que lodos de ETA podem ser convertidos em matérias-primas econômica e ambientalmente sustentáveis. 


\section{BIBLIOGRAFIA}

[1] KALACHE, A., VERAS, R.P., RAMOS, L.R. “O envelhecimento da população mundial. Um desafio novo", Revista de Saúde Pública. v. 21, n. 3, pp. 200-210, 1987.

[2] MORAES, D.S.L., JORDÃO, B.Q. "Degradação de recursos hídricos e seus feitos sobre a saúde humana”, Revista de Saúde Pública. v. 36, n. 3, pp. 370-374, 2002.

[3] JOHN, V.M. Reciclagem de resíduos na construção civil: Contribuição à metodologia de pesquisa e desenvolvimento, Tese de D.Sc, Escola Politécnica, Universidade de São Paulo, São Paulo, SP, Brasil, 2000.

[4] MILLER JR., G.T., Ciência Ambiental, tradução All Tasks, revisão técnica Welington Braz Carvalho Delitti, São Paulo, Cengage Learning, 2014.

[5] BRASIL. MINISTÉRIO DA SAÚDE. Portaria n. 2.914, de 12 dezembro 2011. Dispõe sobre os procedimentos de controle e de vigilância da qualidade da água para o consumo humano e seu padrão de potabilidade.

[6] ASSOCIAÇÃO BRASILEIRA DE NORMAS TÉCNICAS. NBR 10004: Resíduos Sólidos Classificação. Rio de Janeiro, 2004.

[7] BRASIL. Lei n. 12.305, de 02 de agosto de 2010. Política Nacional de Resíduos Sólidos.

[8] ACHON, C.L., BARROSO, M.M., CORDEIRO, J.S., "Resíduos de estações de tratamento de água e a ISO 24512: desafio do saneamento brasileiro", Engenharia Sanitária e Ambiental, v. 18, n. 2, pp. 115-122, 2013.

[9] GERALDO, R.H., FERNANDES, L.F.R., CAMARINI, G., "Water treatment sludge and rice husk ash to sustainable geopolymer production”, Journal of Cleaner Production, v. 149, pp. 146-155, 2017.

[10] BRASIL. Lei n. 9.605, de 12 de fevereiro de 1998. Dispõe sobre as sanções penais e administrativas derivadas de condutas e atividades lesivas ao meio ambiente, e dá outras providências.

[11] BRASIL. Lei n. 9.433, de 8 de Janeiro de 1997. Política Nacional de Recursos Hídricos.

[12] ZEIDEMANN, V.K., “O Rio das Águas Negras”, In: Florestas do Rio Negro, Companhia das Letras, São Paulo, pp. 62-87, 2001.

[13] FRANZINELLI, E. “Características morfológicas da confluência dos rios Negro e Solimões (Amazonas, Brasil)”, Revista Brasileira de Geociências, v. 41, n. 4, pp. 587-596, 2011.

[14] AHMAD, T., AHMAD, K., ALAM, M., "Sustainable management of water treatment sludge through 3'R' concept”, Journal of Cleaner Production, v. 124, pp. 1-13, 2016.

[15] RICHTER, C.A. Tratamento de Lodos de Estações de Tratamento de Água. São Paulo, Edgard Blücher LTDA, 2001.

[16] REALI, M.A.P. (Coordenador), "Principais Características Quantitativas e Qualitativas do Lodo de ETAs”, In: Noções gerais de tratamento e disposição final de lodos de estação de tratamento de água, Projeto PROSAB, ABES, Rio de Janeiro, pp. 20-39, 1999.

[17] OLIVEIRA, E. M. S., MACHADO, S. Q., HOLANDA, J. N. F., “Caracterização de resíduo (lodo) proveniente de estação de tratamento de águas visando sua utilização em cerâmica vermelha", Cerâmica, v. 50, pp. 324-330, 2004.

[18] BOTERO, W.G. Caracterização de lodo gerado em estações de tratamento de água: perspectivas de aplicação agrícola, Dissertação de Mestrado, Universidade Estadual Paulista Júlio de Mesquita Filho, Araraquara, SP, Brasil, 2008.

[19] TARTARI, R., DÍAZ-MORA, N., MÓDENES, A. N. et al., "Lodo gerado na estação de tratamento de água Tamanduá, Foz do Iguaçu, PR, como aditivo em argilas para cerâmica vermelha. Parte I: Caracterização do lodo e de argilas do terceiro planalto paranaense", Cerâmica, v. 57, pp. 288-293, 2011.

[20] PINHEIRO, B.C.A, ESTEVÃO, G.M., SOUZA, D.P., "Lodo proveniente da estação de tratamento de água do município de Leopoldina, MG, para aproveitamento na indústria de cerâmica vermelha Parte I: caracterização do lodo", Revista Matéria, v. 19, n. 03, pp. 204-211, 2014.

[21] ARAÚJO, F.C., SCALIZE, P.S., ALBUQUERQUE, A. et al., "Caracterização física do resíduo de uma estação de tratamento de água para sua utilização em materiais de construção”, Cerâmica, v. 61, pp. 450-456, 2015. 
[22] TEIXEIRA, S.R., DE SOUZA, S.A., DE SOUZA, N.R. et al., "Efeito da adição de lodo de estação de tratamento de água (ETA) nas propriedades de material cerâmico estrutural”, Cerâmica, v. 52, pp. 215-220, 2006.

[23] MONTEIRO, S.N., ALEXANDRE, J., MARGEM, J.I. et al., "Incorporation of sludge waste from water treatment plant into red ceramic", Construction and Building Materials, v. 22, pp. 1281-1287, 2008.

[24] PAIXÃO, L.C.C., YOSHIMURA, H.N., ESPINOSA, D.C.R. et al., "Efeito da incorporação de lodo de ETA contendo alto teor de ferro em cerâmica argilosa", Cerâmica, v. 54, pp. 63-76, 2008.

[25] OLIVEIRA, E. M. S., HOLANDA, J. N. F., "Influência da adição de resíduo (lodo) de estação de tratamento de águas nas propriedades e microestrutura de cerâmica vermelha”, Cerâmica, v. 54, pp. 167-173, 2008.

[26] VIEIRA, C.M.F., MARGEM, J.I., MONTEIRO, S.N., “Alterações microestruturais de cerâmica argilosa incorporada com lodo de ETA”, Revista Matéria, v. 13, n. 2, pp. 275-281, 2008.

[27] VITORINO, J.P.D., MONTEIRO, S.N., VIEIRA, C.M.F., “Caracterização e incorporação de resíduos provenientes de Estação de Tratamento de Água em cerâmica argilosa”, Cerâmica, v. 55, pp. 385-392, 2009.

[28] CHIANG, K.Y., CHOU, P.H., HUA, C.R. et al., "Lightweight bricks manufactured from water treatment sludge and rice husks", Journal of Hazardous Materials, 171, pp. 76-82, 2009.

[29] TARTARI, R., MÓDENES, A. N., PIANARO, S. A., et al., "Lodo gerado na estação de tratamento de água Tamanduá, Foz do Iguaçu, PR, como aditivo em argilas para cerâmica vermelha. Parte II: Incorporação do lodo em mistura de argilas para produção de cerâmica vermelha", Cerâmica, v. 57, pp. 387-394, 2011.

[30] TEIXEIRA, S.R., SANTOS, G.T.A., SOUZA, A.E. et al., "The effect of incorporation of a Brazilian water treatment plant sludge on the properties of ceramic materials", Applied Clay Science, v. 53, pp. 561$565,2011$.

[31] KIZINIEVIC, O., ZURAUSKIENE, R. KIZINIEVIC, V. et al., "Utilisation of sludge waste from water treatment for ceramic products”, Construction and Building Materials, v. 41, pp. 464-473, 2013.

[32] RODRIGUES, L.P., HOLANDA, J.N.F., "Influência da incorporação de lodo de estação de tratamento de água (ETA) nas propriedades tecnológicas de tijolos solo-cimento”, Cerâmica, v. 59, pp. 551-556, 2013.

[33] HOPPEN, C., PORTELLA, K.F., JOUKOSKI, A. et al., "Co-disposição de lodo centrifugado de Estação de Tratamento de Água (ETA) em matriz de concreto: método alternativo de preservação ambiental", Cerâmica, v. 51, pp. 85-95, 2005.

[34] HOPPEN, C., PORTELLA, K.F., JOUKOSKI, A. et al., "Uso de lodo de estação de tratamento de água centrifugado em matriz de concreto de cimento Portland para reduzir o impacto ambiental”, Química Nova, v. 29, n. 1, pp. 79-84, 2006.

[35] TAFAREL, N.F. MACIOSKI, G., CARVALHO, K.Q. et al., "Avaliação das propriedades do concreto devido à incorporação de lodo de estação de tratamento de água”, Revista Matéria, v. 21, n. 4, pp. 974-986, 2016.

[36] CHEN, H.X., MA, X., DAI, H.J., "Reuse of water purification sludge as raw material in cement production”, Cement \& Concrete Composites, v. 32, pp. 436-439, 2010.

[37] RODRÍGUEZ, N.H., RAMÍREZ, S.M., VARELA, M.T.B. et al., "Re-use of drinking water treatment plant (DWTP) sludge: Characterization and technological behaviour of cement mortars with atomized sludge additions", Cement and Concrete Research, v. 40, pp. 778-786, 2010.

[38] OWAID, H.M., HAMID, R., TAHA, M.R., "Influence of thermally activated alum sludge ash on the engineering properties of multiple-blended binders concretes", Construction and Building Materials, v. 61, pp. 216-229, 2014.

[39] GASTALDINI, A.L.G., HENGEN, M.F., GASTALDINI, M.C.C. et al., "The use of water treatment plant sludge ash as a mineral addition”, Construction and Building Materials, v. 94, pp. 513-520, 2015.

[40] TANTAWY, M.A., "Characterization and pozzolanic properties of calcined alum sludge”, Materials Research Bulletin, v. 61, pp. 415-421, 2015.

[41] SALES, A., SOUZA, F.R., ALMEIDA, F.C.R., "Mechanical properties of concrete produced with a composite of water treatment sludge and sawdust", Construction and Building Materials, v. 25, pp. 27932798, 2011.

[42] ANDRADE, C., MYNRINE, V., SILVA, D.A. et al., "Compósito para a construção civil a partir de resíduos industriais”, Revista Matéria, v. 21, n. 2, pp. 321-329, 2016. 
[43] WAIJAREAN, N., ASAVAPISIT, S., SOMBATSOMPOP, K., "Strength and microstructure of water treatment residue-based geopolymers containing heavy metals", Construction and Building Materials, v. 50, pp. 486-491, 2014.

[44] NIMWINYA, E., ARJHARN, W., HORPIBULSUK, S. et al., "A sustainable calcined water treatment sludge and rice husk ash Geopolymer”, Journal of Cleaner Production, v. 119, pp. 128-134, 2016.

[45] MESSINA, F., FERONE, C., MOLINO, A. et al., "Synergistic recycling of calcined clayey sediments and water potabilization sludge as geopolymer precursors: Upscaling from binders to precast paving cementfree bricks", Construction and Building Materials, v. 133, pp. 14-26, 2017.

[46] HORPIBULSUK, S., SUKSIRIPATTANAPONG, C., SAMINGTHONG, W. et al., "Durability against Wetting-Drying Cycles of Water Treatment Sludge-Fly Ash Geopolymer and Water Treatment SludgeCement and Silty Clay-Cement Systems", Journal of Materials in Civil Engineering, ASCE, v. 04015078, pp. 1-9, 2015.

[47] SUKSIRIPATTANAPONG, C., HORPIBULSUK, S., CHANPRASERT, P. et al., "Compressive strength development in fly ash geopolymer masonry units manufactured from water treatment sludge", Construction and Building Materials, v. 82, pp. 20-30, 2015a.

[48] SUKSIRIPATTANAPONG, C., HORPIBULSUK, S., BOONGRASAN, S. et al., "Unit weight, strength and microstructure of a water treatment sludge-fly ash lightweight cellular geopolymer", Construction and Building Materials, v. 94, pp. 807-816, 2015 b.

[49] FERNANDEZ, R., MARTIRENA, F., SCRIVENER, K.L., "The origin of the pozzolanic activity of calcined clay minerals: A comparison between kaolinite, illite and montmorillonite", Cement and Concrete Research, v. 41, pp. 113-122, 2011.

[50] RASHAD, A.M., "Metakaolin as cementitious material: History, scours, production and composition A comprehensive overview", Construction and Building Materials, v. 41, pp. 303-318, 2013.

[51] SABIR, B.B., WILD, S., BAI, J., "Metakaolin and calcined clays as pozzolans for concrete: a review", Cement \& Concrete Composites, v. 23, pp. 441-454, 2001.

[52] ASSOCIAÇÃO BRASILEIRA DE NORMAS TÉCNICAS. NBR 6502: Rochas e solos - Terminologia. Rio de Janeiro, 1995. 